\title{
The effectiveness of acceptance and commitment therapy (ACT) on distress tolerance and the severity of obsessive-compulsive symptoms
}

\author{
Mahboobeh Yarahmadi ${ }^{1}$, Mohammad Oraki ${ }^{2}$, Seyed Hassan Saadat ${ }^{3}$, Mohammad Eshaghian ${ }^{4}$, \\ Arya Momeni ${ }^{5}$ \\ 1-MA of Clinical Psychology, Department of Psychology, South Tehran Branch, Payame Noor University, Tehran, \\ Iran (Corresponding Author). $\quad$ E-mail: yarahmadimahboubeh @ gmail.com \\ 2- Associate Professor, Department of Psychology, South Tehran Branch, Payame Noor University, Tehran, Iran. \\ 3- Assistant Professor, Department of Psychology, Baqiyatallah University of Medical Sciences, Tehran, Iran. \\ 4- Neurologist, Doroud, Iran. \\ 5- Phd Student in Health Psychology, Department of Psychology, Central Tehran Branch, Azad University, Tehran, \\ Iran.
}

Received: $15 / 10 / 2020$

Accepted: 26/12/2020

\begin{abstract}
Introduction: Obsessive-compulsive disorder is a chronic psychological disorder that causes serious damage to the mental, emotional and communication health of patients.

Aim: The aim of this study was to evaluate the effectiveness of acceptance and commitment therapy (ACT), on distress tolerance and the severity of obsessive-compulsive disorder (OCD).

Method: This study was designed using a Quasi-experimental method and pre-test, post-test as and control group. The study population included all patients referred to the psychiatric ward of Mostafa Khomeini Hospital in Dorood between 2018 and 2019. For this purpose, 20 patients with OCD were selected by convenience sampling and assigned to two groups of ACT and control. Each group was tested before and after the intervention by the Yale-Brown scale and the distress tolerance questionnaire (DTQ). The experimental group received 8 sessions of treatment based on ACT and the control group was not subjected to therapy. Data were analyzed by multivariate analysis of covariance (MANCOVA) through SPSS Statistics 24 and presented by descriptive and inferential statistics.
\end{abstract}

Results: The results suggest that ACT had a significant statistical effect on reducing OCD symptoms $(\mathrm{P}=0.000, \mathrm{~F}=92.503)$ and increasing distress tolerance $(\mathrm{P}=0 / 000, \mathrm{~F}=33.889)$. Its effect on the obsession and distress tolerance variables was $87.7 \%$ and $72.3 \%$, respectively.

Conclusion: Considering the therapeutic elements of ACT and its coordination with the psychological problems of OCD, it can be a suitable therapy for these patients.

Keywords: Acceptance and commitment therapy, Obsessive-compulsive disorder, Distress tolerance

How to cite this article : Yarahmadi M, Oraki M, Saadat SH, Eshaghian M, momeni A. The effectiveness of acceptance and commitment therapy (ACT) on distress tolerance and the severity of obsessive-compulsive symptoms. Shenakht Journal of Psychology and Psychiatry. 2021; 7 (6): 66-79 .URL: http://shenakht.muk.ac.ir/article-1-905-en.pdf

Copyright $\odot 2018$ the Author (s). Published by Kurdistan University of Medical Sciences. This is an open access article distributed under the terms of the Creative Commons Attribution-Non Commercial License 4.0 (CCBY-NC), where it is permissible to download, share, remix, transform, and buildup the work provided it is properly cited. The work cannot be used commercially without permission from the journal. 


\title{
اثربخشى درمان مبتنى بر تعهد و يذيرش بر تحمل يريشانى و شدت وسواس فكرى عملى

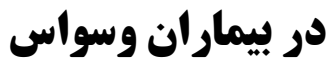

\begin{abstract}
محبوبه ياراحمدى'، محمد اور كى '، سيد حسن سعادت'، محمد اسحاقيان؛، آريا مومنى ا. كارشناس ارشد روانشناسى بالينى، گروه روانشناسى، واحد تهران جنوب، دانشخاه ييام نور، تهران، ايران (مولف مسئول). ايميل:yarahmadimahboubeh@gmail.com

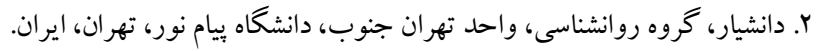

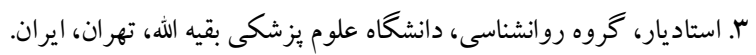
F. بز بزك متخصص اعصاب و روان، دورود، ايران.

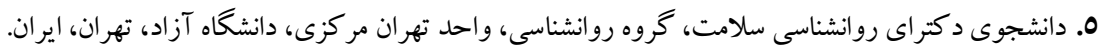

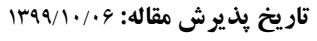

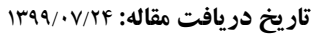

جكيده

مقدمه: يكى از اختلالهاى روانشناختى مزمن كه سلامت روانى، هيجانى و ارتباطى افراد مبتلا را با آسيب جدى مواجه مىسازد، اختلال وسواس فكرى عملى است. هدف: هدف از ئزوهش حاضر بررسى اثربخشى درمان مبتنى بر تعهد و بذيرش بر تحمل يريشانى و شدت وسواس فكرى عملى در

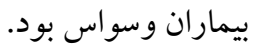

روش: طرح يزوهش نيمه آزمايشى و از نوع بيش آزمون- يٍ آزمون با گروه گ گواه بود. جامعه آمارى كليه بيماران مراجعه كننده به

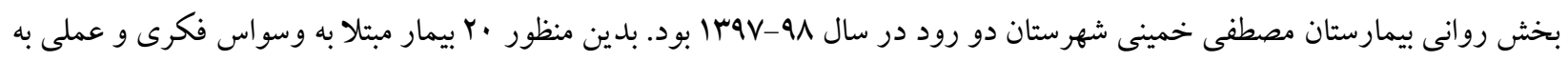

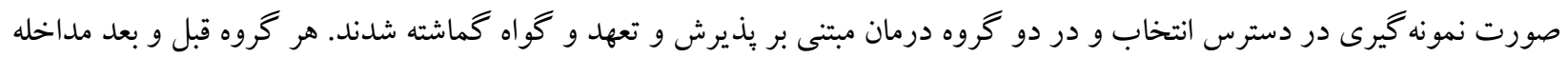

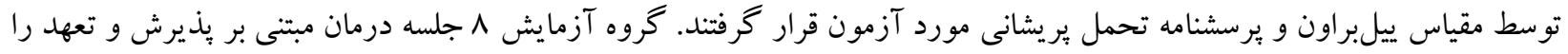

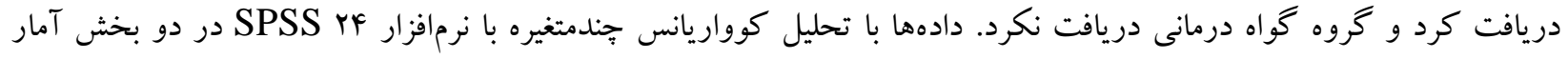
توصيفى و استنباطى تحليل گرديد.

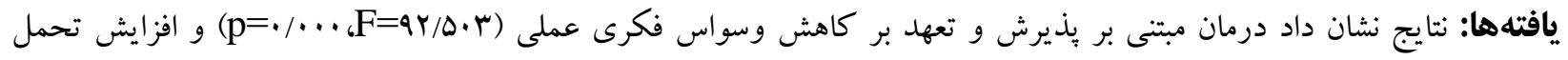

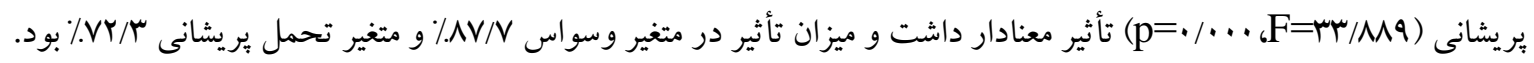
نتيجه كيرى: با توجه به عناصر درمانى درمان مبتى بر يذيرش و تعهد و هماهنكى آن با مشكلات روانشناختى وسواس، مىتواند رواندرمانى مناسبى براى اين افراد باشد. كليدوازهها: درمان مبتى بر بذيرش و تعهد، وسواس فكرى و عملى، تحمل بريشانى 
دارويى، اگر جهه اين درمانها معتبر و مفيد هستند ؛اما

تحقيقات نشان داده كه برخى بيماران با اين روشها بهبود كمى حاصل مى كنند و با نشانها باقى مى مانند و همجِنان اختلال در عملكرد دارند. برخى از بيماران توان تحمل اضطر اب حاصل از مواجهه و جلو گيرى از ياسخ را ندارند و يا جنين درمانى را نمى يسندند (ايزدى و عابدى، بوسا). اخيراً يكى از استراتزىهاى درمانى براى اصلاح اثربخشى رانى درمان براى افراد وسواسى درمان مبتنى بر بذيرش و تعهد

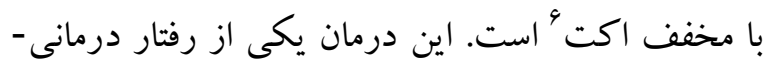
هاى مبتنى بر ذهن آكاهى است كه اين فرض را دارد كه فرايندهاى روانشناختى ذهن انسان اغلب مخرب و و موجب رنج روانشناختى هستند. اين رويكرد در مقايسه با

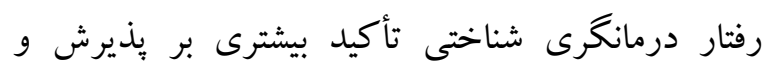
تمايل به تجربه رويدادهاى درونى دارد. به جالش نكشيدن افكار منفى و تغيير آنها از ديخر ويز گحى هاى اين

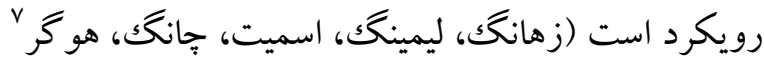
و هيز، Y) (Y). درمان يذيرش و تعهد از شش فرايند تشكيل شده كه اين شش فرايند منجر به انعطافيذيرى روانشناختى ^ مىشوند. اين شش فرايند عبارتاند از:

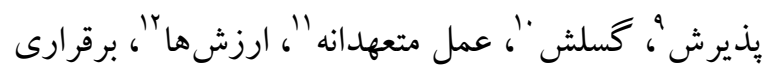
تماس با لحظه حال" و و خود زمينهاى" ميرزائيان، لهوب(). در اكت از درمانجويان خواسته مىشود بيذيرند كه رنج، بخشى از تجربه طبيعى انسان است.

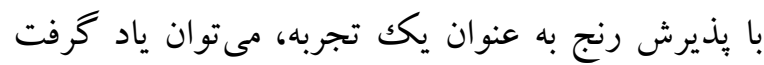

6- Acceptance and Commitment Therapy (ACT)

${ }^{7}$ - Zhang, Leeming, Smith, Chung \& Hagger

${ }^{8}$ - Psychological flexibility

${ }^{9}$ - Acceptance

${ }^{10}$ - Defusion

${ }^{11}$ - Commitment

${ }^{12}$ - Values

${ }^{13}$ - Contact with present moment

${ }^{14}$ - Self as context
يكى از اختلالهاى روانشناختى مزمن كه سلامت روانى، هيجانى و ارتباطى افراد مبتلا را با آسيب جدى مواجه مى سازد، اختلال وسو اس فكرى عملى ' است. اين اختلال به عنوان يكى از اختلالهاى روانشناختى آسيبزا، به وسيله افكار تكرارشونده، مقاوم و رفتارهاى تكرارى همراه با اضطراب شناخته مىشود. عموم افراد مبتلا، داراى هر دو علائم فكرى و عملى هستند. افكار و اعمال تكرارى حاصل از اين اختلال، امورى لذتبخش و ارادى نيستند. اين افكار به شكل غير ارادى بروز كرده و معمولاً

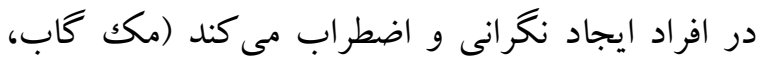
رووا، فارل، يانگك، سويينسون و آنتونى '، 19 19). وسواس فكرى عملى به عنوان يكى از شايعترين و وله ناتوان كنندهترين اختلالات روانشناختى مطرح شده و ونس جهارمين اختلال بعد از فوبيا، سوءمصرف مواد و افسردگى است. اين اختلال روى ها ا تا ب درصد جمعيت افراد بالغ تأثير مى گذارد. اكر وسواس درمان نشود اثرات منفى قابلتوجهى بر زندكى اشخاص مى گذارد. جِون مواجههى دائم با وسواسها و اجبارها در طول روز مىتواند باعث آشفتخى و تنش، اختلال در روابط، شغل

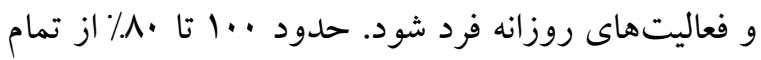
افراد مبتلا به وسواس شديد، اختلال شديد در خانه، محل كار و روابط را گزارش مى كنند (راسكيو، اشتين، جيو و

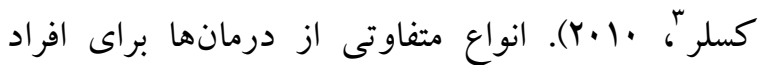
وسواسى استفاده مىشود همجِون درمانهاى شناختى

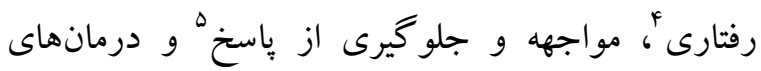

\footnotetext{
1 - Obsessive Compulsive Disorder

${ }^{2}$ - McCabe, Rowa, Farrell, Young, Swinson \& Antony

${ }^{3}$ - Ruscio, Stein, Chiu \& Kessler

${ }^{4}$ - Cognitive Behavior Therapy(CBT)

5 - Exposure and Response Prevention
} 
تحقيقات اخير روى اكت نتايج رضايتبخش و دلايل منطقى براى استفاده از اكت در كار فراهم كردهاند.

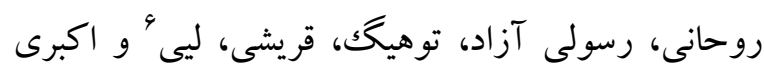

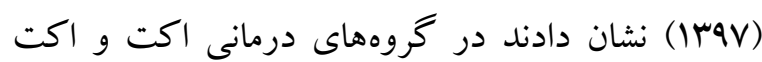

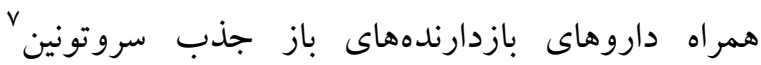

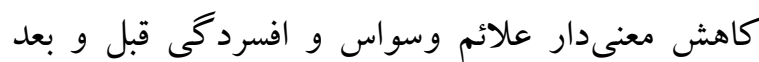
مداخله مشاهده شد؛ و اين كاهش در علائم در گروه اكت همراه داروهاى بازدارنده باز جذب سروتونين بيشتر بود. شعبانى، محسن آبادى، اريك ^، توهيگ، احمدوند و زنجانى (1 (1) در مطالعه خود به اين نتيجه رسيدند كه شرايط اكت همراه داروهاى بازدارنده باز جذب سروتونين و گروه بازدارندههاى باز جذب سروتونين و شناختى رفتارى كاهش قابل توجهى در شدت وسواس را نسبت به شرايط بازدارندهاى باز جذب سروتونين نشان

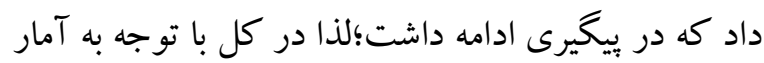
شيوع بالاى اين اختلال، سن بيايين شروع بيمارى و از

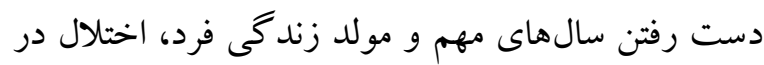
كار و ساير امور زندگى فرد، آسيب به خانواده و اطرافيان، اثربخشى كم و ناكافى ساير درمانها لزوم يرداختن به درمانهاى اثربخشتر همجون اكت براى بيماران وسواسى ضرورى به نظر مىرسد. از طرفى فرد وسواسى دجار انعطافنايذيرى روانشناختى است؛ يعنى تحمل وبريشانى و اضطراب در او بسيار كم است؛ لذا با توجه به اينكه تا به حال هيج تحقيقى تأثير درمان اكت را بر تحمل بريشانى بررسى نكرده در اين تحقيق همجِنين به بر بـى اين مسئله برداخته شد.

6. Lee

${ }^{7}$ - Selective Serotonin Reaptake Inhibitors (SSRIs)

${ }^{8}$ - Eric
كه به آن، ياسخ ساز كارانه ترى داد (ازهاى، سيدشيرازى،

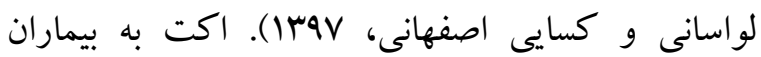
آموزش مىدهد كه رابطه جديدى با افكار وسواسى و هيجانهاى اضطر ابىشان ايجاد كنند براى مثال با در نظر

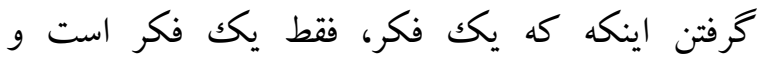
اضطراب تنها يكك هيجان است، به توجه بيماران كمك يك مى كند. اكت به بيماران كمكك مى كند تا به عمل براى به خدمت گرفتن ارزشهاى زندگى متعهد باشد، به جاى بهى اينكه زمان زيادى راصرف تلاش براى كاهش وسواس و يا اجتناب از احساسات اضطرابى كند؛ بنابراين اكت انعطاف يذيرى روانشناختى (توانايى براى تلاش مطابق جهت گيرىهاى برمعناى زندگى بدون توجه به تجربيات

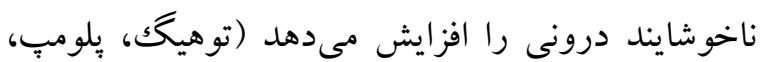

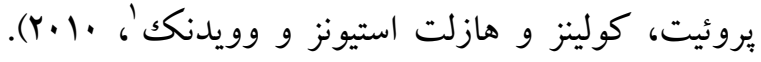
تحمل بريشانى توانايى فرد در تجربه و تحمل حالت هيجانى منفى تعريف شده است (مانينگ، راجرز،

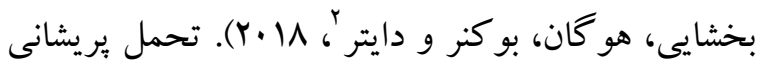
به طور فزايندهاى، به عنوان يكك ساختار مهم در رشد بينشى جديد درباره شروع و ابقاى آسيبهاى روانى و همجنين بيشخيرى و و درمان مشاهده شده است

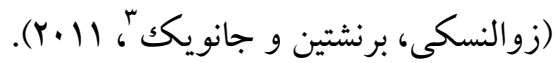

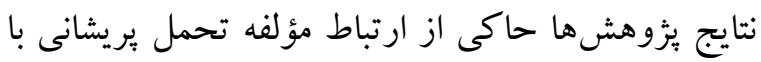

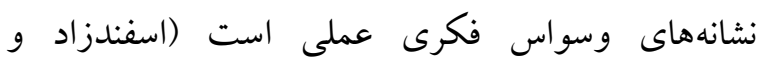
همكاران، هوبا؛ كو گل، تيميانو، فيجو هو كينگ

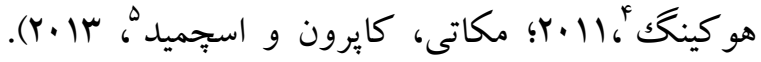

1- Twohig, Hayes, Plumb, Pruitt, Collins, Hazlett-Stevens\& Woidneck

${ }^{2}$ - Manning, Rogers, Bakhshaie, Hogan, Buckner, Ditre

${ }^{3}$ - Zvolensky, Bernstein, Vujanovic

${ }^{4}$ - Cougle، Timpano، Fitch \& Hawkins

5 - Macatee، Capron \& Schmidt 
يثزوهش و نحوهُ تكميل برسشنامها، تأكيد نمود كه روش يرسشنامهها بىنام بوده و اطلاعات آنها محرمانه باقى خواهد ماند و در هر زمان كه مايل باشند مىتوانند از مطالعه خارج شوند. يّ از نمونه گيرى، يك جل جلسه

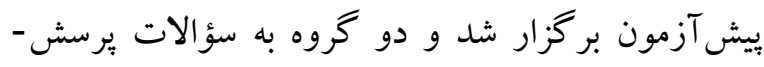

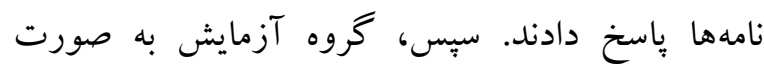
گروهى ^ جلسه دو ساعته درمان اكت را دريافت كرد و كروه كنترل هيج مداخلهاى دريافت نكرد. يس از اتمام جلسات، از هر دو گروه بس آزمون به عمل آمد. روش هرو

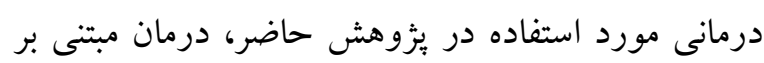
يذيرش و تعهد بر اساس برنامه بروتكل درمانى هيز و

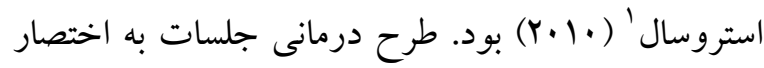
در جدول الارائه شده است. بيش از تجزيهوتحليل دادهها، ابتدا مفروضههاى لازم براى تحليل كوواريانس، مانند برابرى نرمال بودن توزيع نمرات در جامعه (با استفاده از

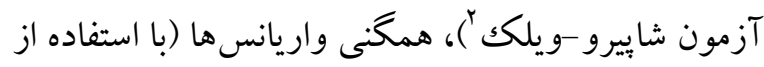

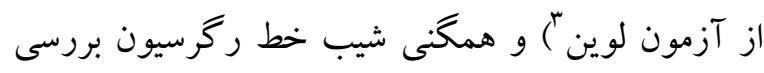
شد و يس از اطمينان از بر آورده شدن ملاككهاى لازم،

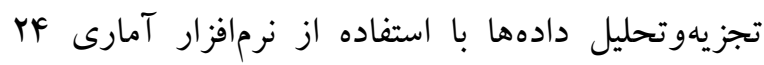
SPSS به كار گيرى روش هاى آمار توصيفى، ميانگين و انحراف -

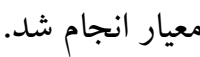

1- Hayes \& Strosahl

${ }^{2}$ - Shapiro-Wilk Test

${ }^{3}$ - Levine test

${ }^{4}$ - MANCOVA طرح تحقيق از نوع نيمه آزمايشى از نوع بيش آزمونبس آزمون با گروه كنترل بود. جامعه آمارى كليه بيماران مراجعه كننده به بخش روانى بيمارستان سيد مصطفى

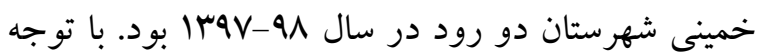
به جامعه آمارى محدود نحوه نمونه گيرى به شيوه در دسترس بود. به دليل مراجعه تدريجى بيماران به بيمارستان، امكان گمارش تصادفى نمونهها در گرووهاى درمانى نيز وجود نداشت. حدود اس نفر بيمار وسواسى به

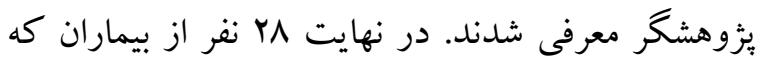
بالاترين نمرات را (به عنوان خط پيايه) پِ از تكميل يرسشنامها كسب كردند (در مقياس ييل براون، نمرات بالاتر از Y Y و در مقياس تحمل بريشانى نمرات كمتر از

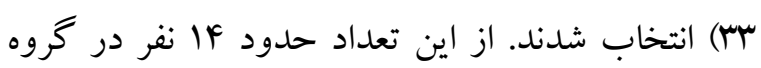
درمان مبتنى بر بذيرش و تعهد و بقيه در ليست انتظار قرار

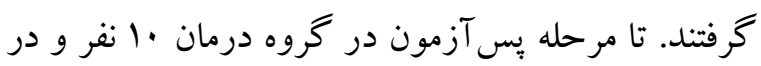
كروه انتظار · ل نفر باقى ماندند.

ملاككهاى ورود نمونه به تحقيق شامل تشخيص اختلال وسواس فكرى- عملى بر حسب راهنماى تشخيصى آمارى اختلالات روانى ويرايش بنجم، مقطع سنى بين 19 تا •4 سال، حداقل تحصيلات سوم راهنمايى و رضايت مندى از شركت در يثوهش بود. ملاككهاى خروج نمونه از تحقيق شامل دريافت هر گونه درمان روانشناختى و دارويى در شش ماه كذشته و وجود اختلالات روان يزشكى شديد مثل اسكيزوفرنيا، اختلال دوقطبى، آسيب-

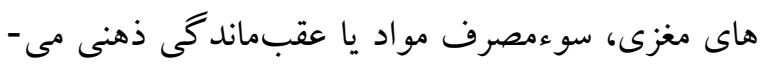
شد. در مرحلهُ اجراى بثزوهش، بزوهشخر ابتدا خود رابه ليه

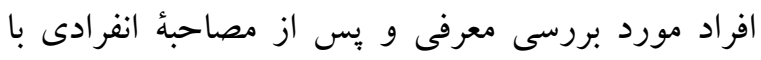

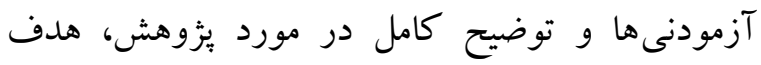


اثربخشى درمان مبتى بر تعهد و يذيرش بر تحمل بريشانى و شدت وسواس فكرى عملى در بيماران وسواس

جدول ا خلاصه جلسات درمان اكت

\begin{tabular}{|c|c|}
\hline واى جلسه & جلسه \\
\hline رى رابطه مناسب با هدف ير كردن صحيح يرسشنامهها و ايجاد اعتماد و اجراى بيش آزمون & 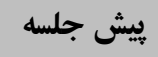 \\
\hline درباره وسواس، درمانگر، آشنايى اعضا با يكديخر و برقرارى رابطهى درمانى؛ استعاره دو كوه، معرفى درمان اكت، ارائه اطلاعات & جلسة اول \\
\hline تمرورى بر تجارب جلسهى قبل و دريافت بازخورد از مراجعه كند كان؛ بحث در مورد تجربيات و ارزيابى آنها؛ ارزيابى & 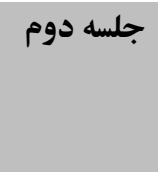 \\
\hline 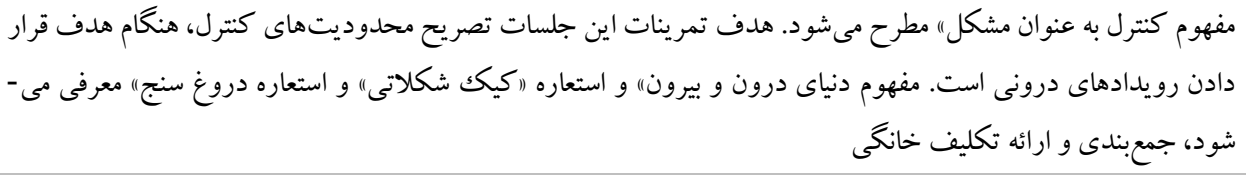 & 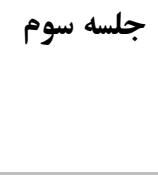 \\
\hline 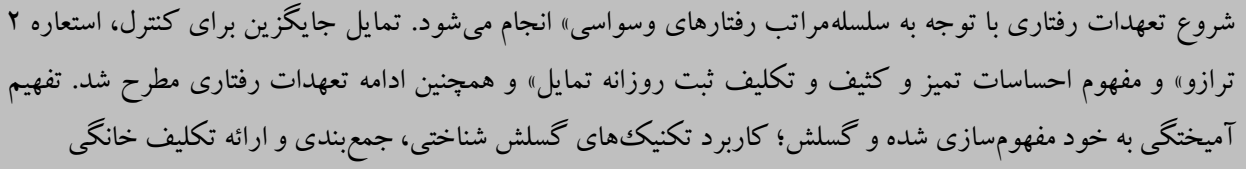 & جلسه جهارم \\
\hline 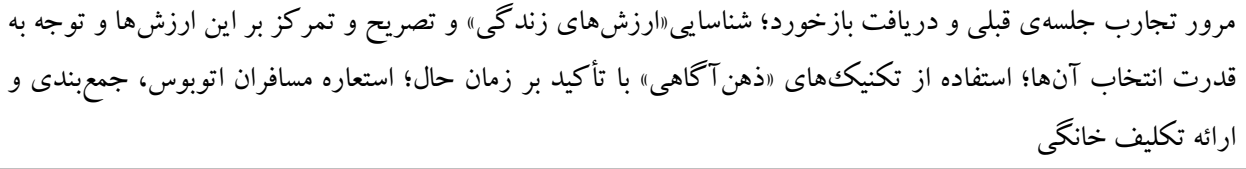 & جلسه ينجم \\
\hline 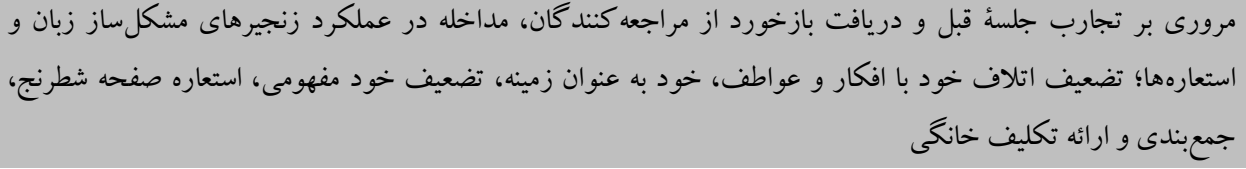 & جلسه ششم \\
\hline 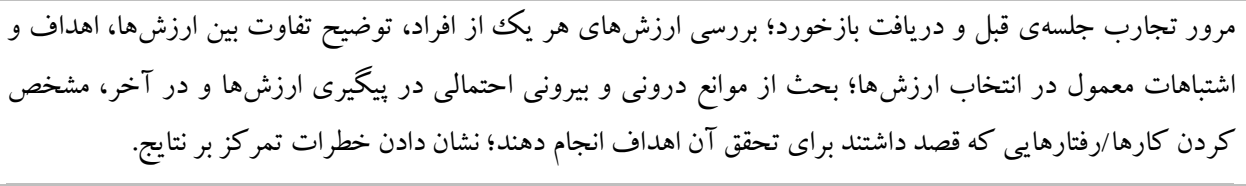 & جلسه هفتم \\
\hline 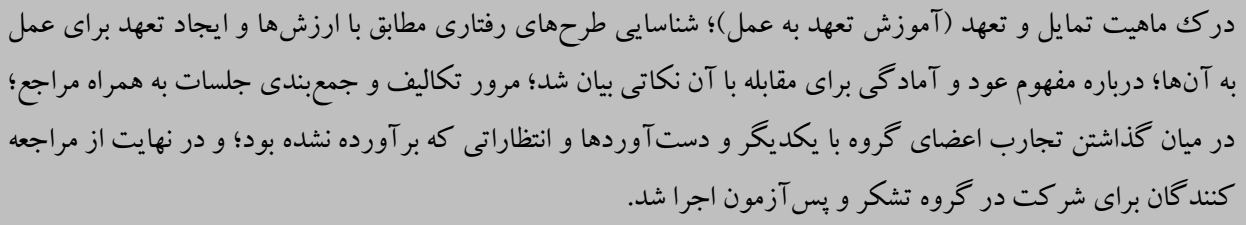 & جلسه هشتم \\
\hline
\end{tabular}

شدن به وسيله هيجانات منفى)، ارزيابى (بر آورد ذهنى يريشانى) و تنظيم (تنظيم كوششها براى تسكين يرسشنامه تحمل يريشانى'؛ يكك مقياس خود سنجى است

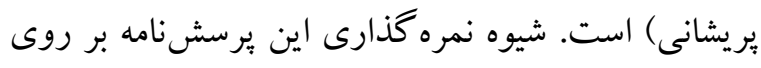

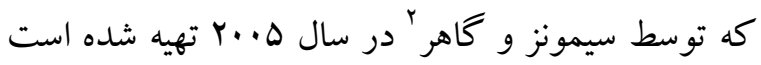

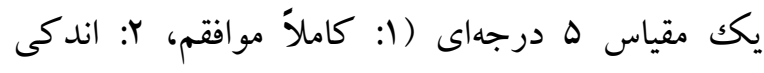
و ها كويه و F خرده مقياس دارد. خرده مقياسهاى آن موافقم؛ س: نه موافقم و نه مخالف، \&: اندكى مخالفم، ه: شامل: تحمل (تحمل يريشانى هيجانى)، جذب (جذب

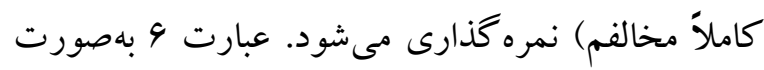
معكوس نمره كذارى مىشود. براى به دست آوردن

\footnotetext{
${ }^{1}$ - Distress tolerance scale; DTS

${ }^{2}$ - Simons \& Gaher
} 
وسواس متوسط، بيشتر از ما وسواس شديد هستند.

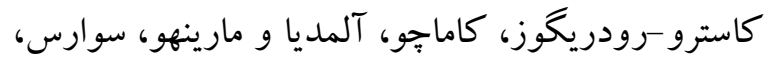

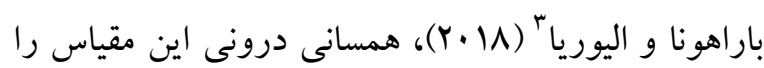

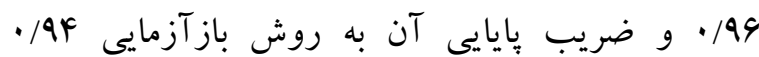
برآورد كردند. در ايران راجزى اصفهانى و همكاران

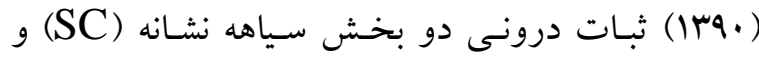

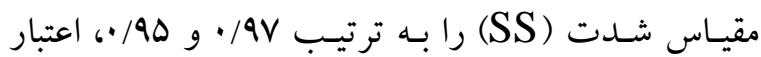

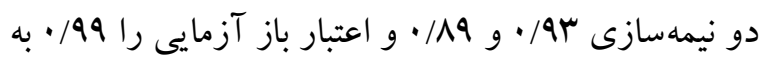

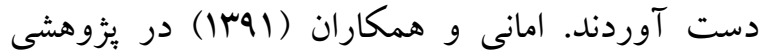
ضمن بررسى روايى صورى اين ابزار به بررسى ضريب

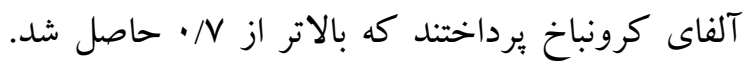
قندهارى زاده و همكاران (IrqV) ضريب آلفاى كرونباخ را براى اين برسشنامه را سV/• به دست آوردند.

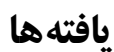

دادهاى جمعيت شناختى آزمودنىها نشان داد كه ميانگين سنى در گروه آزمايش ه/AV استاندارد س/4/است. تحصيلات دييلم در هر دو گروه با F مرصد بيشترين ميزان را به خود اختصاص داده است.

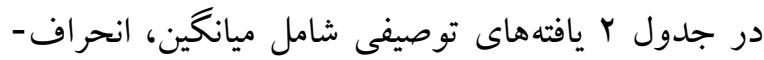
معيارمتغيرهاى يُوهش شامل تحمل بريشانى، كاهش وسواس فكرى عملى در دو گروه آزمايش و كنترل ارائه

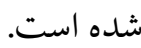

3 - Castro-Rodrigues, Camacho, Almeida, Marinho, Soares, Barahona-Corrêa \& Oliveira-Maia
تحمل بريشانى كلى نمره تمام سؤالات با هم جمع مى شود و براى به دست آوردن نمره هر يك از ابعاد، نمره سؤالهاى هر بعد با هم جمع مىشوند. نمر ات بالا در اين مقياس نشان گر تحمل بريشانى بالاست (سيمونز و كاهر، هـ.r). سيمونز و كاهر، ضرايب آلفا را براى اين مقياس

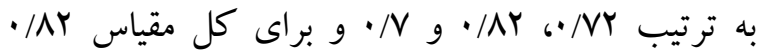
بر آورد كردهاند. آنها همجِنين بيان كردهاند كه بر سشنامه

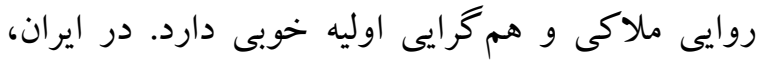

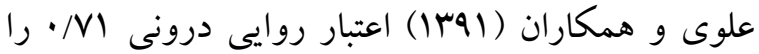
براى اين مقياس به دست آوردهاند. اسماعيلى نسب و و

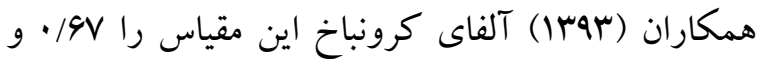
ضريب اعتبار باز آزمايى براى كل مقياس را الام/• و براى زير مقياسهاى تحمل، جذب، ارزيابى و تنظيم به ترتيب، إس مقياس وسواس فكرى- عملى ييل براون '؛ يك مصاحبه

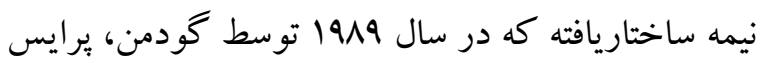
و راسموسن ' ساخته شد و داراى مقياس شدت و مقياس علائم وسواس فكرى و عملى است و · إخويه دارد كه ميزان شدت وسواس را در شرايط كنونى بيمارى ارزيابى

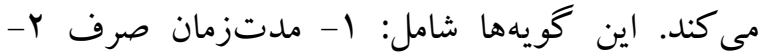

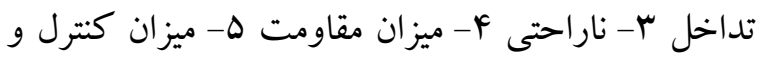
علائم افكار و اعمال وسواسى را جداكانه مىسنجد.

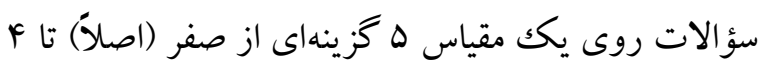
(شديد تا سخت) درجهبندى مىشود. براى نمره كذارى

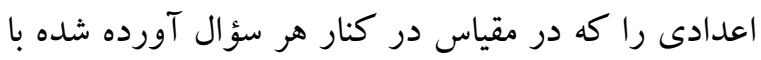
هم جمع كرده، نمرات كمتر از • ا، وسواس بسيار

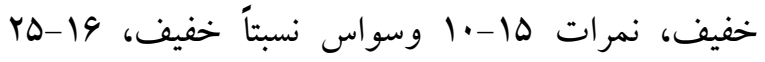

\footnotetext{
1- Yale-Brown Obsessive Compulsive Scale:YBOCS

${ }^{2}$ - Goodman, Price \& Rasmussen.
} 


\begin{tabular}{|c|c|c|c|c|c|}
\hline \multicolumn{2}{|c|}{ ֶֻ آزمون } & \multicolumn{2}{|c|}{ يِيش آزمون } & \multirow{2}{*}{ شاخصهاى } & \multirow[t]{2}{*}{ مقياس } \\
\hline كواه & آزمايش & آزمايش & كواه & & \\
\hline$r \mathrm{r} / \mathrm{.}$ & $\Delta \Delta / \wedge \ldots$ & $r q / r .$. & $r q / r \ldots$ & ميانگين & تحمل يويشانى \\
\hline $9 / 410$ & $\mid r / 919$ & $q / 4 q$. & $q / \mu q$. & انحراف معيار & \\
\hline$r q / \mu .$. & $9 / \wedge \cdots$ & $r \Delta / 1 \ldots$ & $r \varepsilon / r .$. & ميانگين & وسواس فكرى عملى \\
\hline$\Delta / V \Delta \Delta$ & r/4Aq & $0 / 494$ & $\Delta / V \Delta \Delta$ & انحراف معيار & \\
\hline
\end{tabular}

همانطور كه در جدول Y ملاحظه مىشود، در مرحلهى همخنى واريانسها (آزمون لوين)، همخنى ضرايب

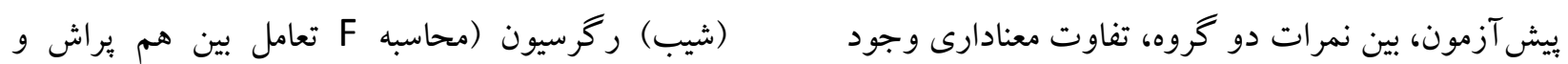
مستقل) بررسى و در مورد متغيرها تائيد شد (ه •/ > > (p). نداشته است؛ اما در مرحلهى يس آزمون، ميانگين نمرات به منظور بررسى اثربخشى اكت بر متغيرهاى بزوهش از تحمل بريشانى در اثر استفاده از برنامه درمانى اكت در تحليل كوواريانس جند متغيره استفاده شد. در اين آزمون كروه آزمايش نسبت به گرووه كنترل افزايش يافت و از جنانجه سطح معنىدارى از هـ/ • كمتر باشد فرضيه طرفى ميانگين نمرات وسواس فكرى عملى بس إن از اثربخشى تأييد و جنانجه اين سطح از هـ • • بيشتر باشد اين مداخله در گروه آزمايش نسبت به گروه كنترل كاهش فرضيه رد خواهد شد. جدول (r) اختلاف معنادارى بين يافت. با توجه به اينكه طرح يزوهش ييش آزمون- يس نمرات دو گروه كنترل و آزمايش، يس از خارج كردن آزمون با گروه كنترل است؛ لذا بهترين تحليل، تحليل تأثير بيش آزمون را نشان مىدهد. كوواريانس است. يُيشفرض هاى تحليل كوواريانس شامل توزيع نرمال متغير وابسته (آزمون شاييروويلك)،

جدول r نتايج تحليل كوواريانس متغيرهاى ثزوهش

\begin{tabular}{|c|c|c|c|c|c|c|c|c|}
\hline آمارى & تأثيز & معنادارى & $\mathbf{F}$ & مجذانكين & درجادى & مجذوروات & منبع خطا & \\
\hline - & - & $\cdot 19 \cdot 4$ & . TAK & $\Delta / V Y$. & 1 & $\Delta / V Y$. & بِيش آزمون & وسواس \\
\hline.$/ 99$ & $\cdot / A V V$ &.$/ \cdots$ & $Q Y / \Delta \cdot r$ & $1 A V Y / 9.9$ & 1 & $1 A V Y / 9.9$ & كروه & \\
\hline - & - & - & - & $Y \cdot / Y F V$ & ir & $r g r / r l$. & خطا & \\
\hline - & - & . & $1 / \Delta \wedge r$ & $\| F / v \cdot F$ & 1 & $\| F / v \cdot F$ & ييش آزمون & تحمل ير يشانى \\
\hline.$/ 9 F$ & . MYr &.$/ \cdots$ & $r r / M q q$ & 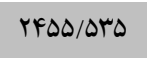 & 1 & 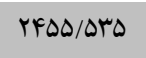 & كروه & \\
\hline - & - & - & - & $V Y / F \Delta \Lambda$ & ir & QFI/QDr & خطا & \\
\hline- & - & - & - & - & - & - & بيش آزمون & مؤلفه تحمل \\
\hline$\cdot / 91$ & $\cdot, V Y$. & $\cdot / \cdots$ & MT/FFA & $1.1 / 914$ & 1 & $1.1 / 914$ & كروه & \\
\hline - & - & - & - & $r / \cdot \mu \Lambda$ & Ir & $r q / F q F$ & خطا & \\
\hline - & - & - & - & - & - & - & بيش آزمون & مؤلفه جذب \\
\hline
\end{tabular}




\begin{tabular}{|c|c|c|c|c|c|c|c|c|}
\hline.$/ 91$ & .1949 &.$/ \cdots$ & $Y Y / \cdot V \Delta$ & 1.v/rur & 1 & l. & كروه & \\
\hline- & - & - & - & F/AGT & ir & $9 \pi / Y 19$ & خطا & \\
\hline- & - & - & - & - & - & - & بيش آزمون & \multirow[t]{3}{*}{ مؤلفه ارزيابى } \\
\hline$\cdot / 9 V$ & .1940 &.$/ \cdots$ & $r \mu / \Delta \wedge V$ & TrY/Iq. & 1 & YYY/IQ. & گروه & \\
\hline- & - & - & - & $11, \Delta I V$ & ir & $\mid Y Y / F \Delta Q$ & خطا & \\
\hline- & - & . /OYF & - & - & - & - & ييش آزمون & \multirow[t]{3}{*}{ مؤلفه تنظيم } \\
\hline$\cdot / 9$ & $\cdot / \Delta V F$ &.$/ \cdots$ & IV/DY & $r \cdot 1 / \Lambda \cdot \Delta$ & 1 & $r \cdot I / A \cdot \Delta$ & كروه & \\
\hline- & - & - & - & $r \cdot / Y F V$ & Ir & $|F q / V| V$ & خطا & \\
\hline
\end{tabular}

موجب افزايش تحمل بريشانى و كاهش شدت وسواس

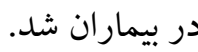

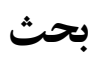

هدف اين بثزوهش بررسسى اثربخشى درمان مبتنى بر يذيرش و تعهل بر تحمل بريشانى و شدت وسواس فكرى عملى در بيماران وسواسى بود. ميانخين نمرات وسواس كروه درمان مبتنى بر يذيرش و تعهد نسبت به گرووه گو اه،

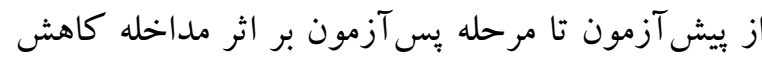
يافته است؛ لذا يافتهاى اين تحقيق حاكى از اثربخشى اين درمان در بهبود علائم وسواس در بيماران مبتلا به وسواس فكرى عملى است. اين يافته را مىتوان با مطالعه توهيگك و آبراموئيز، اسميت، فابريكانت، جاكوبى،

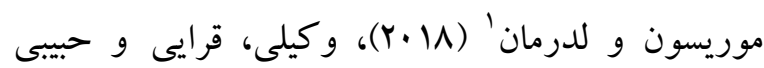

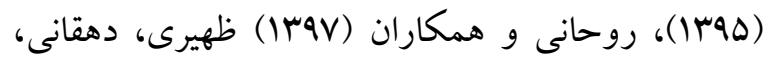
ايزدى (و (1) همسو دانست. اين يزوهشخران به اتفاق نشان دادهاند كه درمان مبتنى بر يذيرش و تعهد مى تواند موجب كاهش وسواس هاى فكرى و عملى شود. در تبيين اثربخشى اكت بر شدت وسواس فكرى عملى

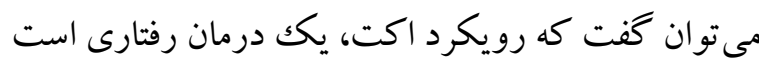

1- Twohig, Abramowitz, Smith, Fabricant, Jacoby, Morrison \& Ledermann.
نتايج جدول ط نشان مىدهد كه اختلاف معنىدارى بين دو گروه آزمايش و كنترل در متغيرهاى بيزوهش (تحمل يريشانى و وسواس فكرى عملى) وجود دارد (ه •/ > (p). جدول ب نشان مىدهد كه يس از خارج كردن اثر ييشآزمون بين گروههاى آزمايش و كواه، اختلاف

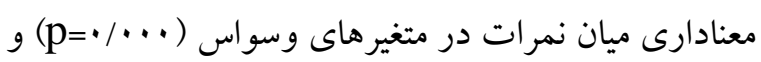

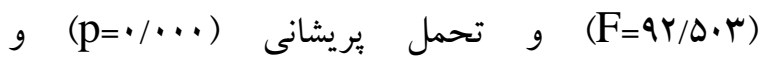
هر دو گروه وجود داشت؛ بنابراين فرضيه (F/M/M9) صفر معنادار نبودن اختلاف ميانگين دو گروه دوه درو يس آزمون يس از حذف اثر احتمالى يِيش آزمون رد

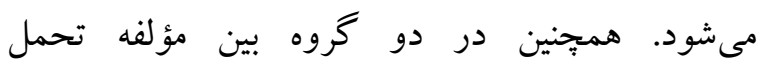
( $)$ و ( $p=\bullet / \cdots)$

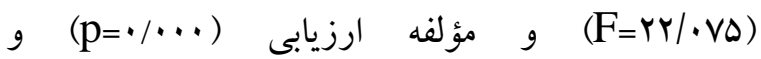

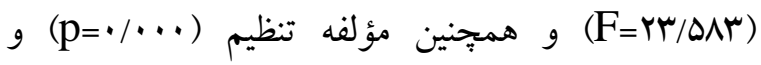
تفاوت معنادارى وجود دارد. ميزان تأثير نيز $(F=$ VV/DYM) نشان مىدهد كـه عضويت گروهى در مرحله بـ -

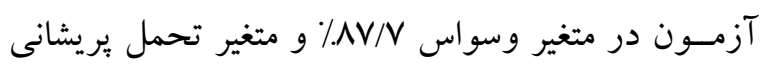
r/VY\% از تفاوت واريانسهاى نمرات وسواس و تحمل بريشانى آزمودنى ها را تبيين مى كند. توان آمارى بالاتر از

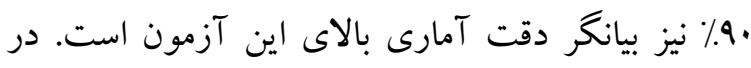

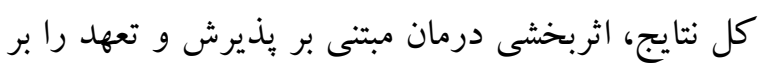
متغيرهاى بُزوهش به اثبات مىرساند؛ يعنى درمان اكت 
(IMqV)

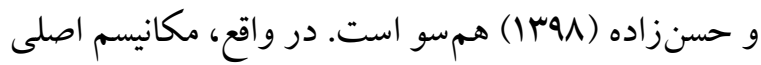
اثر گذارى اين روش درمانى، در جلسات درمانى اين بُزوهش متمركز بر اين نكته بود كه بيماران به جاى اين كه بر روى برطرف سازى و حذف عوامل آسيبزا

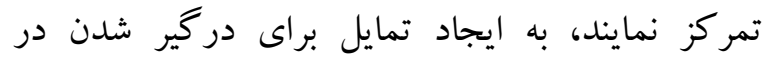
اهداف و فعاليتهاى ارزشمند شخص تأكيد كنند؛ بنابراين، وقتى به بيماران آموزش داده مىشود كه هيجانات و احساسات خود را بدون به كارگيرى مكانيسم هاى دفاعى بيذيرند و بتوانند فارغ از ارزيابى اغراقآميز

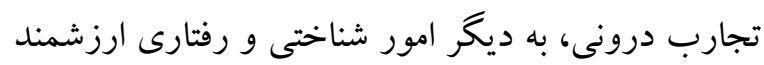
خود ادامه دهند، به طور معمول از ميزان فشار روانى وى كاسته شده، انعطاف يذيرى روانشناختى را افزايش مى دهد (هيز، 19 +Y). راهبردهاى درمانى كه اجتناب را مورد هدف قرار مىدهند، براى افزايش تحمل يريشانى مفيد هستند. يكى از اين راهبردها درمان مبتنى بر يذيرش و

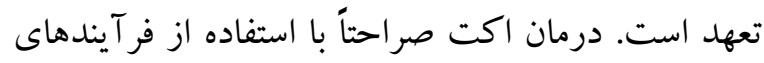
اصلى طراحى شده براى كاهش فرار و اجتناب بى فايده و

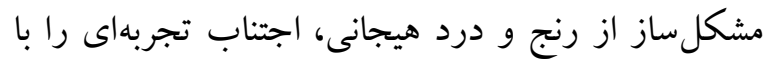
افزايش يذيرش روانى و آكاهى از افكار و احساسات

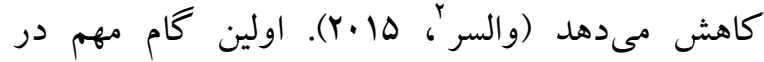
افزايش تحمل يريشانى سالم، آكاهى افزايش يافته از آشفتگى و توانايى قضاوت در مورد ناديده كرفتن يا ياسخ به نشانهاى تنش يا نار احتى است. در اينجا با جايخزين كردن خود، به عنوان زمينه، مر اجعه كنند كان توانستند رويدادهاى درونى ناخوشايند را در زمان حال به سادگى تجربه كنند و قادر به جدا كردن خود از واكنشها، خاطرات و افكار ناخوشايند شدند. در
كه از مهارت ذهن آكاهى، گُسلش شناختى براى افزايش انعطاف يذيرى روان استفاده مى كند و با جايخزين كردن

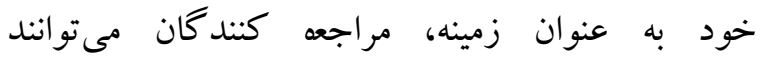
رويدادهاى درونى ناخوشايند را در زمان حال به سادگى تجربه كنند و قادر به جدا كردن خود از واكنشها، خاطرات و افكار ناخوشايند شوند. در واقع در اين نوع درمان به افراد آموزش داده شد كه جّگ نه فر آيندهاى مركزى بازدارى فكر را رها كرده، از افكار آزاردهنده

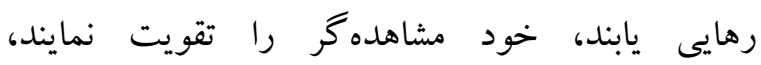
رويدادهاى درونى را به جاى كنترل بيذيرند، ارزشهايشان را تصريح كنند و به آنها بيردازند اين درمان براى بالاتر بردن ميزان يذيرش در بيماران هزينهها و مشكلات كنترل را مطرح مى كند؛ به عبارتى ديخر موضوع مشترك و يايه در تمام مداخلات مبتنى بر يذيرش و تعهد اين است كه كنترل مسئله است نه راهحل

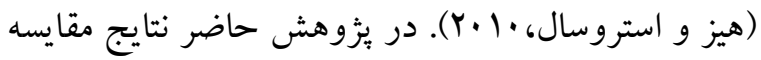
كروه آزمايش با كواه در مقياس ييل براون نشان داد كه

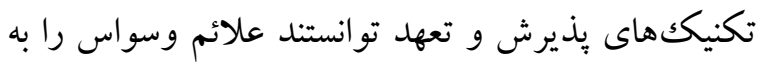
خوبى مورد هدف قرار داده و شدت آن را كاهش دهد. اگر جهه در اين درمان مواجهه درون جلسهاى مورد استفاده قرار نخرفت؛ اما تمرينات تعهد رفتارى كه مواجهه با موقعيتهاى وسواسى در خارج از جلسه را شامل مى شد را در بر داشت. يافتهى ديخر بزوهش حاضر نشان داد كه رواندرمانى به روش اكت در گروه آزمايش موجب افزايش تحمل بريشانى بيماران شد. اين نتيجه با نتايج مطالعات

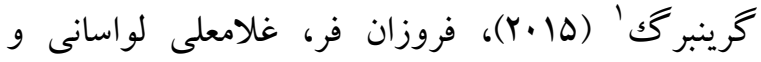
كاظمى (هوبr)، اميريان، مامى، احمديان و محمد زاده 
ديخر تجارب درونى تغيير دهند و آنها را رويدادهاى ذهنى بييند كه يكى بس از ديخرى مى آيند و مىروند. با ديا تجربهى رويدادها به طور كامل و عارى از دفاع، همان-

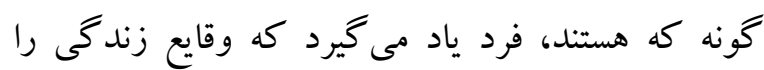
همان گونه كه هسـتند بييند و ســى در دخالت يا عوض كردن آنها نكند؛ لذا در كل نتايج حاصل اين مطالعه نشان مىدهد كه درمان مبتنى بر بِذيرش و تعهل براى

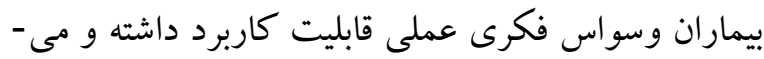
تواند به عنوان مداخلهاى روانشناختى در كنار ساير مداخلات مورد استفاده قرار گيرد و همجنين مىتواند درمان مناسبى براى افزايش تحمل بريشانى و كاهش وسواس بيماران باشد.

\section{نتيجه كيرى}

با توجه به نتايج به دست آمده به نظر مىرسد كه درمان مبتنى بر بذيرش و تعهد به عنوان يكك درمان غنى و جند مؤلفهاى مىتواند در بهبود شدت وسواس فكرى عملى و همجينين افزايش تحمل بريشانى بيماران وسواسى مؤثر باشد. ازجمله محدوديتهاى اين يزوهش عدم امكان انجام مر حلهُ بيخيرى و تعداد نمونه كم به علت محدوديت زمانى و اجراى تحقيق بر روى نمونه در دسترس بود. همجنين در انتخاب نمونه يُوهش حاضر تلاش بر انتخاب بيمارانى بود كه به بيمارىهاى روانيزشكى يا ديخرى مثل اختلال دو قطبى مبتلا نباشند ؛ لذا در تعميم نتايج اين يثزوهش به بيمارانى كه در آنها اين اختلالات مشاهده مىشود، بايد احتياط نمود. بيشنهاد مى شود اجراى تحقيق

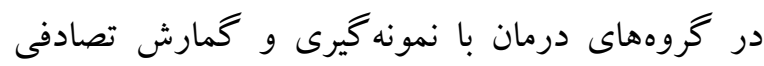
براى حصول اطمينان بيشتر به يافتهاى ئزوهشى، اجراى

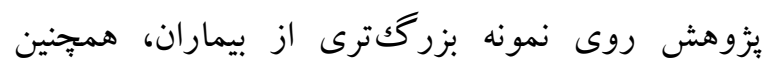

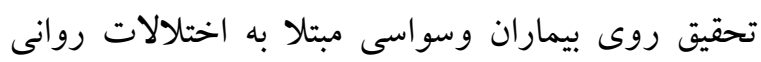

واقع در اين نوع درمان به افراد آموزش داده شد كه جֶّونه فر آيندهاى مركزى بازدارى فكر را رها كرده، از افكار آزاردهنده رهايى يابند، به جاى خود مفهومسازى شده، خود مشاهدهُ را تقويت نمايند، رويدادهاى درونى را بهجاى كنترل بيذيرند، ارزش هايشان را تصريح كنند و به آنها بيردازند. همجِين در اين درمان افراد ياد مى گيرند كه احساسات خود را بيذيرند تا اينكه از آنها فاصله بحيرند و به افكار و فر آيند تفكرشان بهوسيله ذهن آكاهى بيشتر برداخته و آنها را در راستاى فعاليتهاى هدف محور وبيوند دهند (توهيگ و همكاران، 11)

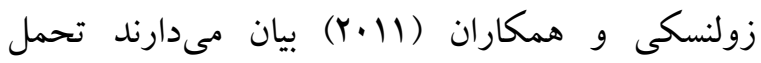
بريشانى سالم، آكاهى از افكار و احساسات درونى و هيجانها و توانايى عدم ياسخدهى واكنشى و خود كار و بدون آكاهى به موقعيت هاى آزاردهنده را كاهش مى دهد؛ به عبارتى عدم تحمل بريشانى و رفتارهاى بيش - بـ بـ تحملى احتمالاً بدون آكاهى هشيار رخ ميدهد. در جلسات درمان اكت تمرينهاى ذهن آكًاهى و تماس با لحظه حال مورد تأكيد قرار مى گيرند. بيماران وسواسى

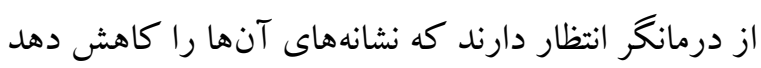
دارد؛ اما در درمان اكت تمركز به جاى كاهش نشانهها بر زندگى ارزشمند است (هيز و استروسال، •(1). ترغيب بيماران به روشن كردن ارزشها، تعيين اهداف، بيشبينى

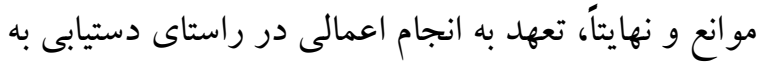
اهداف و حركت در جهت ارزشها، علىرغم وجود بيمارى باعث مىشود تا ضمن تحقق اهداف و شادكامى ناشى از آنكه بر عزتنفس و خود كار آمدى بيمار مى افزايد، او را از كير افتادن در حلقهاى از افكار و احساسات منفى رها مى كند؛ به به عبارتى اكت اكت مر اجعه كنند كان را تشويق مى كند رابطهشان را با افكار و 
Oliveira-Maia A. (2018). Criterion Validity of the Yale-Brown Obsessive-Compulsive Scale Second Edition for Diagnosis of ObsessiveCompulsive Disorder in Adults. Frontiers in Psychiatery. 10, 3389.

Cougle JR, Timpano KR, Fitch KE, Hawkins KA. (2011). Distress tolerance and obsessions: an integrative analysis. Depression and anxiety, 28(10), 906-14.

Ebrahimpour GH, Mirzaeian B, Hasanzade R. (2019). Effectiveness of acceptance and commitment therapy on psychological well-being, quality of life and depression in patients with epilepsy. Journal of Shahid Sadoughi University of Medical Sciences, 27(2), 1262-79. (In Persian).

Ejei J, Sayadshirazy M, Gholamali Lavasani M, Kasaei Esfahani A. (2018). Compare the Effectiveness of Group Therapy Based on Acceptance and Commitment and CognitiveBehavioral Therapy on Reducing Anxiety of Mothers of Autistic Children. Journal of Psychology, 22 (1), 3-21. (In Persian).

Esfandzad A, Shams G, Meisami A, Erfan A. (2016). The role of mindfulness, emotional regulation, distress tolerance and effective communication with others in predicting symptoms Algebraic obsession. Iranian Joumal of Psychiatry and Clinical Psychology, 22(4), 270- 83. (In Persian).

Esmaeili Nasab M, Andami Khoshk AR, Azarmi H, Samar Rakhi A. (2014). The predicting role of difficulties in emotion regulation and distress tolerance in students' addiction potential. J Res Addict, 8(29), 49-63. (In Persian).

Forouzanfar A, Gholamali Lavasani M, Shoa Kazemi M. (2018). The effectiveness of group counselling based on acceptance and commitment therapy in distress tolerance and anxiety sensitivity among female substance abusers. J Res Addict, 11(44), 135-54. (In Persian).

Gandaharizadeh A, Aghamohammadian H, Bagheri F. (2018). The Effectiveness of Psychological Well-being Treatment on Obsessive -

$$
\begin{aligned}
& \text { ديخر انجام شود و بررسى اثربخشى درمان مبتنى بر } \\
& \text { يذيرش و تعهد در ردهاى سنى كودكى و نوجوان نيز } \\
& \text { تو صيه مىشود. } \\
& \text { سياسگز ارى } \\
& \text { مقاله حاضر بخشى از باياننامه دوره ارشد به شماره كد }
\end{aligned}
$$

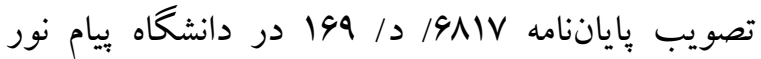

$$
\begin{aligned}
& \text { تهران جنوب مىباشد. يُزوهشگران لازم مىداند از } \\
& \text { همكارى صميمانه افرادى كه در گروههاى آزمايش و } \\
& \text { كنترل شركت كردند، تشكر و سِّاس گزارى نمايند. }
\end{aligned}
$$

\section{References}

Ahmadi A, Raeisi Z. (2018). The effect of acceptance and commitment therapy on distress tolerance in mothers of children with autism. Quarterly Journal of Child Mental Health, 5(3), 59-79. (In Persian).

Alavi K, Modarres Gharavi M, Amin-Yazdi SA, Salehi Fadardi J. (2011). Effectiveness of group dialectical behavior therapy (based on core mindfulness, distress tolerance and emotion regulation components) on depressive symptoms in university students. Journal of Fundamentals of Mental Health, 13(50), 124 135. (In Persian).

Amani M. (2011). The effectiveness of inferential treatment on the reduction of obsessivecompulsive and practical symptoms. Clin Psychol Res Consult, 5(12), 55-68. (In Persian).

Amirian K, Mami SH, Ahmadi V, Mohamadzadeh J. (2018). Effectiveness of Group Psychotherapy Based on Acceptance and Commitment Therapy on Difficulties Emotion Regulation and Distress Tolerance in Substance Abusers. Journal of Education and Community Health, 5(18), 53-61. (InPersian).

Castro-Rodrigues P, Camacho M, Almeida S, Marinho M, Soares C, Barahona-Comêa J, 
compulsive Disorder Improvement and the Fear of Negative Evaluation of Women with Washing Compulsive. Iranian Journal of Psychiatric Nursing, 6(4), 27-33. (In Persian).

Goodman WK, Price LH, Rasmussen SA. (1989). The Yale-Brown obsessive-compulsive scale (YBOCS), Part I: Development, use, and reliability. Journal of Archives of General Psychiatry, 46, 1006-1011.

Greenberg LP. (2015). The flexibility of distress tolerance through a brief Acceptance and Commitment Therapy intervention: A pilot study, doctoral dissertation.

Hayes SC, Strosahl KD, (2010). A Practical Guide to Acceptance and Commitment Therapy. New York: Springer Science and Business Media Inc.

Hayes SC. (2016). Acceptance and Commitment Therapy, Relational Frame Theory, and the Third Wave of Behavioral and Cognitive Therapies-Republished Article. Journal Behavior therapy, 47(6), 869-885.

Izadi R, Abedi MR. (2013). Alleviation of obsessive symptoms in treatment-resistant obsessivecompulsive disorder using acceptance and commitment-based therapy. Feyz, Journal of Kashan University of Medical Sciences, 17(3), 275-286. (In Persian).

Izakian S, Mirzaian B, Hosseini SH. (2019). The Effectiveness of Acceptance and Commitment Therapy on Emotion Dysregulation and Self-Compassion Among Self-Harm Students. Journal of Thought \& Behavior in Clinical Psychology, 14(53), 1726. (In Persian).

Macatee RJ, Capron DW, Schmidt NB, Cougle JR. (2013). An examination of low distress tolerance and life stressors as factors underlying obsessions. Journal of psychiatric research, 47(10), 14628.

Manning K, Rogers AH, Bakhshaie J, Hogan JBD, Buckner JD, Ditre JW, Zvolensky MJ. (2018). The association between perceived distress tolerance and cannabis use problems, cannabis withdrawal symptoms, and self-efficacy for quitting cannabis: The explanatory role of pain-related affective distress. Addictive Behaviors, 85, 1-7.

McCabe RE, Rowa K, Farrell NR, Young L, Swinson RP, Antony M. (2019). Improving treatment outcome in obsessive-compulsive disorder: Does motivational interviewing boost efficacy. Journal of Obsessive-Compulsive and Related Disorders, 22, 100446.

Rajezi Esfahani S, Motaghipour Y, Kamkari K, Zahiredin A, Janbozorgi M. (2010). Reliability and Validity of the Persian Version of the Yale-Brown Obsessive-Compulsive Scale (Y-BOCS). Iranian Journal of Psychiatry and Clinical Psychology, 17(4), 297-303. (In Persian).

Rohani F, Rasouli-azad M, Twohigb MP, Ghoreishic FS, Lee EB, Akbarid H. (2018). Preliminary test of group acceptance and commitment therapy on obsessivecompulsive disorder for patients on optimal dose of selective serotonin reuptake inhibitors. Journal of ObsessiveCompulsive and Related Disorder, 16, 8-13. (In Persian).

Ruscio A, Stein D, Chiu W, Kessler R. (2010). The epidemiology of obsessive-compulsive disorder in the National Comorbidity Survey Replication. Molecular psychiatry, 15(1), 5363.

Shabani MJ, Mohsenabadi H, Omidi A, Eric B, Twhig M, Ahmadvand A, Zanjani Z. (2019). An Iranian study of group acceptance and commitment therapy versus group cognitive behavioral therapy for adolescents with obsessive-compulsive disorder on an optimal dose of selective serotonin reuptake inhibitors. Journal of Obsessive-Compulsive and Related Disorders, 22, 1-38. (In Persian).

Simons JS, Gaher RM. (2005). The distress tolerance scale: Development and validation of a selfreport measure. Motiv Emot, 29(2), 83-102.

Twohig MP, Abramowitz JS, Smith BM, Fabricant LE, Jacoby RJ, Morrison KL, Ledermann T. (2018). Adding acceptance and commitment therapy to exposure and response prevention 
for obsessive-compulsive disorder: A randomized controlled trial. Behaviour Research and Therapy, 108, 1-9.

Twohig MP, Hayes HC, Plumb JS, Pruitt LD, Collins $\mathrm{AB}$, Hazlett-Stevens $\mathrm{H}$, Michelle $\mathrm{R}$, Woidneck MR. (2010). A randomized clinical trial of acceptance and commitment therapy versus progressive relaxation training for obsessive-compulsive disorder. National Center for Biotechnology Information, 78(5), 705-16.

Vakili Y, Gharaee B, Habibi M. (2016). Acceptance and Commitment Therapy, Selective Serotonin Reuptake Inhibitors and Their Combination in the Improvement of Obsessive-Compulsive Symptoms and Experiential Avoidance in Patients With Obsessive-Compulsive Disorder. Iranian Journals Psychyarty and Behavioral Sciences, 9(2), 10-14. (In Persian).

Walser RD, Garvert DW, Karlin BE, Trockel M, Ryu DM, Taylor CB. (2015). Effectiveness of Acceptance and Commitment Therapy in treating depression and suicidal ideation in Veterans. Behaviour reseaarch and therapy, 74, 25-31.

Zahiri S, Dehghani A, Izadi R. (2018). The Effectiveness of Acceptance and Commitment Therapy (ACT) Enriched with Compassion Focus Therapy (CFT) on Obsession Symptoms of Students with ObsessiveCompulsive Disorder. Psychological Studies, 13(4), 93-110. (In Persian).

Zhang CQ, Leeming E, Smith P, Chung PK, Hagger MS, Hayes SC. (2018). Acceptance and commitment therapy for health behavior change: a contextuallydriven approach. Journal Frontiers in psychology, 8, 2350.

Zvolensky MJ, Bernstein A, Vujanovic AA. (2011). Distress tolerance: Theory, Research, and Clinical Application, New York: Guilford Press. 